\title{
Effects of increasing numbers of phagocytic inclusions on human retinal pigment epithelial cells in culture: a model for aging
}

\author{
MIKE BOULTON AND JOHN MARSHALL \\ From the Institute of Ophthalmology, Judd Street, London WC1H $9 Q S$
}

SUMMARY Cultures of human retinal pigment epithelial cells have been challenged with a number of biological (lipofuscin, melanin, and rod outer segments) and non-biological (latex microspheres) particles at a variety of concentrations. The particles were chosen to include examples of both degradable and non-degradable systems. A range of morphological changes were observed by phase contrast microscopy, and these became more atypical with increasing concentration. At the highest concentration cells had ingested so many particles that many had died and others had ruptured. The time course of these changes indicated a relationship between cellular lytic activity and the capacity of the particle to degrade. The potential of this system as a model for studying senescence is discussed.

The retinal pigment epithelium (RPE) differentiates early in embryogenesis, and thereafter little if any cell division occurs in this layer' other than in response to acute injury, such as laser induced damage. ${ }^{2}$ With increasing age some cells die and are lost from this layer. Those remaining migrate and increase in surface area to ensure the integrity of the epithelial sheet and maintain its blood-retinal barrier properties. This aging population of cells also has a unique role in phagocytosing the spent tips of rods and cones. ${ }^{34}$ Thus, unlike any other macrophage which has a transient existence and having fulfilled its role by ingesting its target material then dies, the same pigment epithelium cells must continuously engulf photoreceptor elements on a diurnal basis for 70 years or more.

Once inside the pigment epithelium the outer segments undergo lysis, which results in their progressive degradation. 5 Some of the breakdown products of this process may be recycled back to the photoreceptor cells, while others are voided into the choriocapillaris via Bruch's membrane.

The lipofuscin granules seen within the pigment epithelial cells ${ }^{x-11}$ have been attributed to the retention of incompletely degraded remnants of phagocytosed photoreceptor outer segments, ${ }^{6}{ }^{11}$ and as they represent the accumulation of a non-functioning molecule they must be an indication of cell Correspondence to Professor J Marshall. senescence. ${ }^{12}$ Since lipofuscin is not initially extruded from the cell but slowly accumulates with the passing years, it is particularly obvious in the tissues of older people, increasing from $8 \%$ of cell volume to $20 \%$ between the ages 40 and 80 years. This accumulation is particularly apparent in the RPE of the macula, ${ }^{10}$ and has been stated by some authors as the reason why RPE cells from this location grow less actively in culture than those from peripheral sites,${ }^{13}$ the implication being that the higher the lipofuscin content the more 'senile' the cell.

Quantitative analysis of the accumulation of lipofuscin within the RPE is complicated by the presence of melanin granules, as the two may closely resemble each other. Melanin granules are also constantly exposed to lysosomal enzymes ${ }^{14}$ but in general appear to be little affected by them ${ }^{15}$ though melanolysosomes are sometimes identified. ${ }^{16}$ In some instances melanin granules appear in complex inclusions together with lipofuscin; these are termed melanolipofuscin and assume a variety of forms dependent on the dominant component."

Studies of RPE from various animal species have shown that, in addition to phagocytosing the terminal ends of outer segments, the RPE is also capable both in vitro and in vivo of ingesting latex microspheres, carbon particles, liposomes, ${ }^{17-20}$ and, in the case of chick RPE, bacteria. ${ }^{21}$

When human RPE cells are isolated and grown in 
tissue culture the cells become progressively depigmented as a result of the dilution of both melanin and lipofuscin granules among a rapidly increasing number of daughter cells. ${ }^{22}{ }^{23}$ In such situations loss of melanin may decrease the cells' protective mechanisms by removal of both a light absorbing system ${ }^{24}$ and a free radical scavenger. ${ }^{25}$ However, loss of lipofuscin may effectively rejuvenate daughter cells by eradicating a product of senescence. ${ }^{26}$

Previous experiments have shown that depigmented cells will readily ingest both melanin and lipofuscin granules when these are presented in the culture medium and that they will retain the ingested pigment granules within their cell cytoplasm. ${ }^{27}$ This study is an attempt to simulate cellular senescence by challenging cultures of RPE cells with increasing concentrations of a variety of degradable and nondegradable biological particles and non-degradable abiotic particles.

\section{Methods and materials}

CELL CULTURE

Post-mortem eyes from six persons with no known ophthalmic disease were obtained from various hospitals in London. Donor eyes ranged from a 16week fetus to a 91-year-old adult. Eyes from two dystrophic donors were obtained via the British Retinitis Pigmentosa Society's eye donor scheme. One donor was a 4-year-old child with LaurenceMoon-Biedl syndrome and the other a 68-year-old sufferer from retinitis pigmentosa. All eyes were processed between 24 and $48 \mathrm{~h}$ following death.

Human RPE cells were isolated and cultured by the techniques previously described. ${ }^{2329}$ The need to increase the amount of tissue available from any given donor dictated that all cells had undergone four to seven passages.

Cultures for experiments were grown either in eight-chamber tissue culture slides or in $17 \mathrm{~mm}$ multiwells (Flow).

\section{EYE CUP PREPARATION}

Two eyes were received $24 \mathrm{~h}$ post mortem, one from a 7-year-old girl and the other from a 58-year-old man. Eye cups were prepared by a modification of the cylinder technique. ${ }^{2 x}$ The eye cup, devoid of vitreous and neural retina, was dissected into five segments, four segments from the periphery and one from the macular region. Stainless steel cylinders were placed on selected areas of each segment before being filled with either medium alone or medium supplemented with lipofuscin.

Rod outer segment isolation. Bovine rod outer segments were isolated from fresh retinae by the technique of Papermaster. ${ }^{30}$
Melanin and lipofuscin isolation. Melanin and lipofuscin were isolated as previously described. ${ }^{25}$

\section{CHALLENGE}

Confluent cultures of human RPE cells grown on either eight-chamber slides or $17 \mathrm{~mm}$ multiwells were challenged with $0.3 \mathrm{ml}$ or $1 \mathrm{ml}$ respectively of growth medium containing one of the following:

(a) $0.8 \mu \mathrm{m}$ diameter latex microspheres (Sigma), final concentration $3.0 \times 10^{*}, 3.0 \times 10^{7}$, or $3.0 \times 10^{6} / \mathrm{ml}$;

(b) $0.5 \mu \mathrm{m}-1.4 \mu \mathrm{m}$ diameter lipofuscin granules at a final concentration of $3.0 \times 10^{8}, 3.0 \times 10^{7}$, or $3.0 \times 10^{6} / \mathrm{ml}$

(c) melanin granules at a final concentration of $3.0 \times 10^{8}, 3.0 \times 10^{7}$, or $3.0 \times 10^{6} / \mathrm{ml}$ (the dimensions of these fusiform granules were $1.0 \mu \mathrm{m}$ in their short axis and $2.5 \mu \mathrm{m}$ in their long axis);

(d) bovine rod outer segments at a final concentration of $3.0 \times 10^{8}, 3.0 \times 10^{7}$, or $3.0 \times 10^{6} / \mathrm{ml}$ (the dimensions of outer segment fragments ranged from $1.5 \mu \mathrm{m}$ to $4.0 \mu \mathrm{m})$.

At appropriate time periods after challenge (see 'Results') the cells were examined by phase contrast bright field and electron microscopy.

Because of the difficulty in obtaining fresh human donor material both of the specimens obtained within $24 \mathrm{~h}$ post mortem were challenged with an identical medium in an attempt to reduce experimental error. They were both exposed to $0.25 \mathrm{ml}$ of growth medium containing $3.0 \times 10^{*}$ lipofuscin particles per $\mathrm{ml}$ and incubated at $37^{\circ} \mathrm{C}$ in a carbon dioxide incubator. Cells were processed $24 \mathrm{~h}$ after challenge for light microscopy.

\section{MICROSCOPY}

Inverted microscopy. The gross morphological appearance of cell cultures was observed on a number of occasions throughout the exposure period by an inverted microscope (Leitz Diavert). At selected times cultures were rinsed with Dulbecco's phosphate buffered saline (PBSA) and prepared for high resolution microscopy as follows:

Fluorescence microscopy. The cells were fixed for $1 \mathrm{~h}$ at room temperature with $3.5 \%$ paraformaldehyde in PBSA, washed with PBSA, and covered with coverslips wet mounted on glycerol/water (1:1). Slides were examined by a Zeiss fluorescent microscope (a BP-450-490 exciter and an LP 520 barrier filter).

Bright field light, and electron microscopy. The cells were fixed for $2 \mathrm{~h}$ at $4^{\circ} \mathrm{C}$ with $2 \%$ glutaraldehyde in $0.1 \mathrm{M}$ cacodylate buffer, and postfixed for $1 \mathrm{~h}$ at $4^{\circ} \mathrm{C}$ in $1 \%$ osmium tetroxide in $0.1 \mathrm{M}$ cacodylate buffer before being dehydrated in ethanol. Poly/Bed 812 (Polysciences, Inc.), was introduced into the multiwells and polymerised at $60^{\circ} \mathrm{C}$ for $48 \mathrm{~h}$. The 
resin plus cells were detached from the culture substrate and re-embedded in Poly/Bed812 for a further $48 \mathrm{~h}$. Sections were cut on a Reichart OMU4 ultramicrotome and either stained with toluidine blue for light microscopy or mounted on 300 mesh, uncoated copper grids, stained with uranyl acetate and lead citrate, before being examined in an AEI 801 electron microscope.

\section{DETERMINATION OF CELL VIABILITY}

Cell viability was determined by the trypan blue exclusion technique. ${ }^{31}$ A $0.4 \%$ trypan blue solution was either: diluted 1:10 and placed directly on to cells attached to the substrate; or diluted 1:10 with a suspension of cells which had become detached from the substrate. One drop of the suspension was then placed on a slide and mounted with a coverslip.

Cells were examined by bright field light microscopy. Dead cells were defined as those which took up stain within 3-10 minutes of staining.

\section{Results}

All human RPE cells readily phagocytosed latex microspheres, melanin granules, lipofuscin granules, and bovine rod outer segments.

Cells grown on chamber slides showed a number of differing morphological changes which were dependent on the number of particles presented in the challenge. Observation on cultures $24 \mathrm{~h}$ after challenge with the highest concentrations of melanin, lipofuscin, or latex microspheres showed a massive drop-out of cells when compared with unchallenged cultures (Figs. 1 and 2). Those cells remaining were crammed full of granules and had assumed either a stellate or rounded appearance. Between 15 and $30 \%$ of these cells showed uptake of trypan blue, indicating cell death. The overlying medium was full of cell debris, and of the few intact cells in suspension all had taken up trypan blue. Cells in cultures which had received the intermediate particles concentration displayed a morphology with partially rounded profiles when compared with unchallenged cells (Figs. 1 and 2 ). In contrast cells in those cultures that received the lowest challenge dose retained a morphology similar to that of untreated samples (Figs. 1 and 2).

Cultures which had been challenged with bovine rod outer segments showed comparable morphological changes with increasing particle concentration, but the time period required to achieve such changes was longer. Little morphological change was apparent within $24 \mathrm{~h}$ of challenge (Fig. 2), but within two to three days a similar appearance was seen in those cells challenged for $24 \mathrm{~h}$ with melanin, lipofuscin, or latex microspheres.

A similar spectrum of morphological changes to that seen in cultures grown on chamber slides was observed in cells grown in multiwells except that in each case the time scale was extended. Cell detachment following the highest challenge concentration of melanin, lipofuscin, or microspheres did not occur until three to four days after challenge. Again cells challenged with rod outer segments took the longest time to respond, and although they rounded up they did not become detached from the substrate within the time course of the experiment (four days).

Light microscopy showed the cytoplasm of all challenged cells to be congested to varying degrees with particles, and confirmed that the cells had rounded up by reducing the length of their boundary membrane (Fig. 3). All samples of cells challenged with lipofuscin or melanin were examined by fluorescence microscopy to check for cross contamination. There was virtually no contamination of lipofuscin by melanin and only minimal (3-5\%) contamination of melanin with lipofuscin. The purity of our challenges was further verified by electron microscopy.

The eye cup preparations did not provide useful results. In unchallenged specimens that were fixed immediately after dissection, and prior to incubation of fellow samples, RPE cell loss was apparent. The damage to these cells was in part due to post-mortem changes and in part due to physical disturbances induced by handling during isolation of corneal buttons for grafting. The magnitude of this nonspecific cell loss rendered any analysis of further losses due to challenge impossible. These results are disappointing and in contrast to those of Feeney and Mixon. ${ }^{32}$ However, these workers began retinal incubations within four to six hours of death, and concentrated most of their published observations on bovine RPE.

\section{Discussion}

The accumulation of any non-functional molecule or particle within a cell is a sign of increasing senescence. ${ }^{12}$ If accumulation reaches a critical level, thus overwhelming cell renewal and/or replacement mechanisms, senescence proceeds to cell death. The progressive accumulation of lipofuscin within the human RPE cell is unique in that the major part of this waste product or debris is thought to be derived from the phagocytic load imparted by a second cell system, the photoreceptor cells. With loss of available cell volume for organelles engaged in active transport and other metabolic support roles, the decline in aging RPE cells has a rapid feedback, manifesting as a diminishing capacity to cope with the demands of the overlying photoreceptor cells. This cyclic progression may well underlie the generation of the commonest cause of retinal blindness in the 


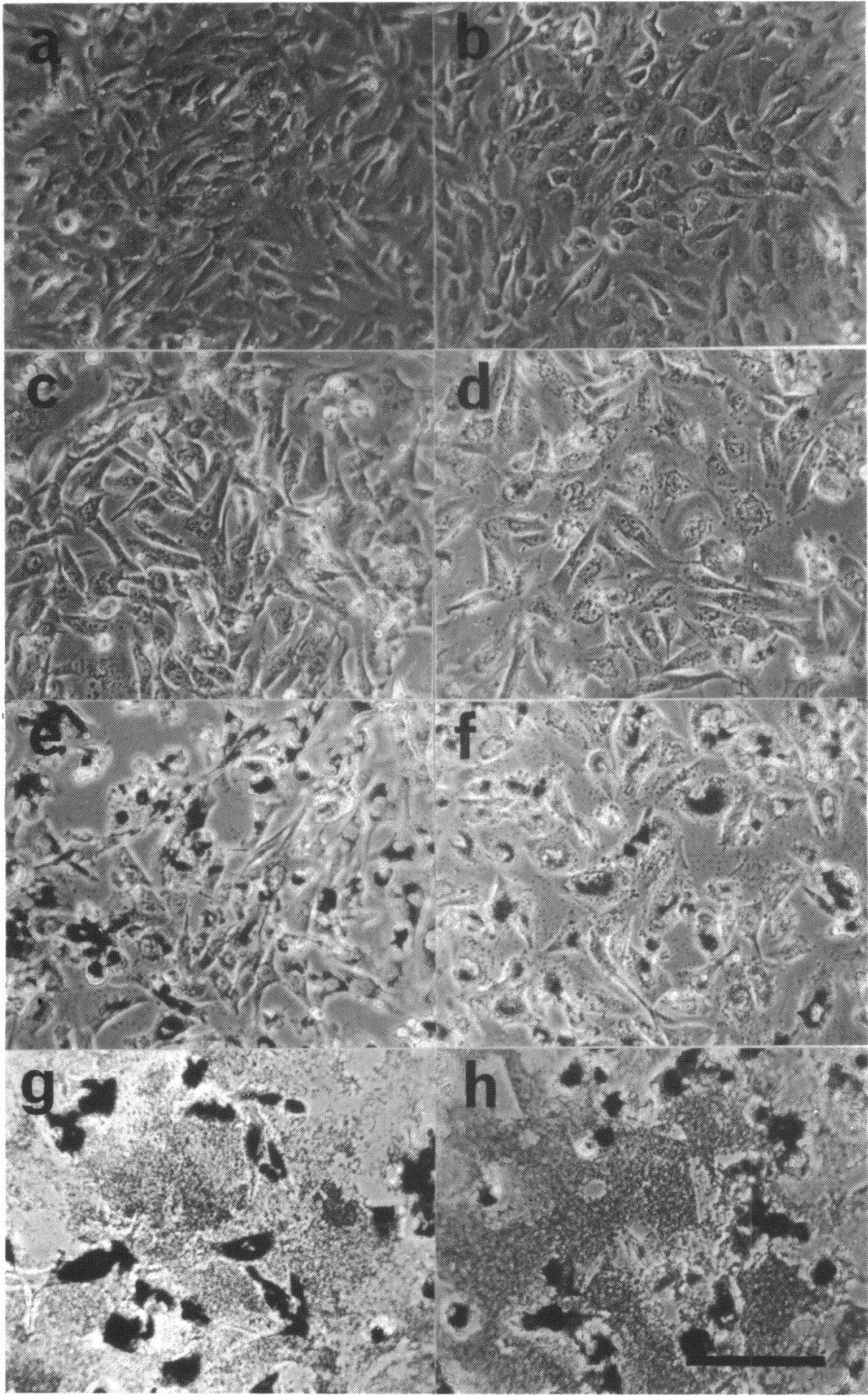

Fig. 1 Light micrographs of human retinal pigment epithelial cells on chamber slides 24 h after challenge with concentrations of $3 \times 10^{h}(\mathrm{c}, \mathrm{d}), 3 \times 10^{7}(\mathrm{e}, \mathrm{f})$, and $3 \times 10^{8}(\mathrm{~g}, \mathrm{~h})$ of melanin $(\mathrm{c}, \mathrm{e}, \mathrm{g})$ and lipofuscin $(\mathrm{d}, \mathrm{f}, \mathrm{h})$ particles. $\mathrm{a}$ and $\mathrm{b}$ are controls and the bar marker is $200 \mu \mathrm{m}$. Note the progressive loss of cell-to-cell continuity.

western world, namely senile macular degeneration. ${ }^{233-35}$

In human RPE in vivo the lipofuscin content increases with increasing age, while at the same time the number of melanin granules reduces as more and more granules are seen in melanolysosomal or melanolipofuscin complexes. ${ }^{36}$ The former are thought to occur both as a result of slowing of the rate constants of enzymes involved in lysis of rod discs and of the progressive development of faults in those chemical reactions which result in only partially digested end products. The latter is thought to arise through an age related loss of cell enzyme specificity in which recognition of self begins to fail.

The selective distribution of high concentrations of lipofuscin within RPE cells at the macula ${ }^{10}$ may reflect either an increased or higher phagocytic load presented to these cells by photoreceptor cells whose 
Fig. 2 Light micrographs of human retinal pigment epithelial cells on chamber slides $24 \mathrm{~h}$ after challenge with concentrations of $3 \times 10^{\circ}(\mathrm{c}, \mathrm{d}), 3 \times 10^{7}(\mathrm{e}, \mathrm{f})$, and (c, e, g) and bovine rod outer segments $(\mathrm{d}, \mathrm{f}, \mathrm{h})$. a and b are controls and the bar marker is $200 \mu \mathrm{m}$. Note the progressive loss of cell-to-cell continuity. $3 \times 10^{*}(\mathrm{~g}, \mathrm{~h})$ of latex microspheres

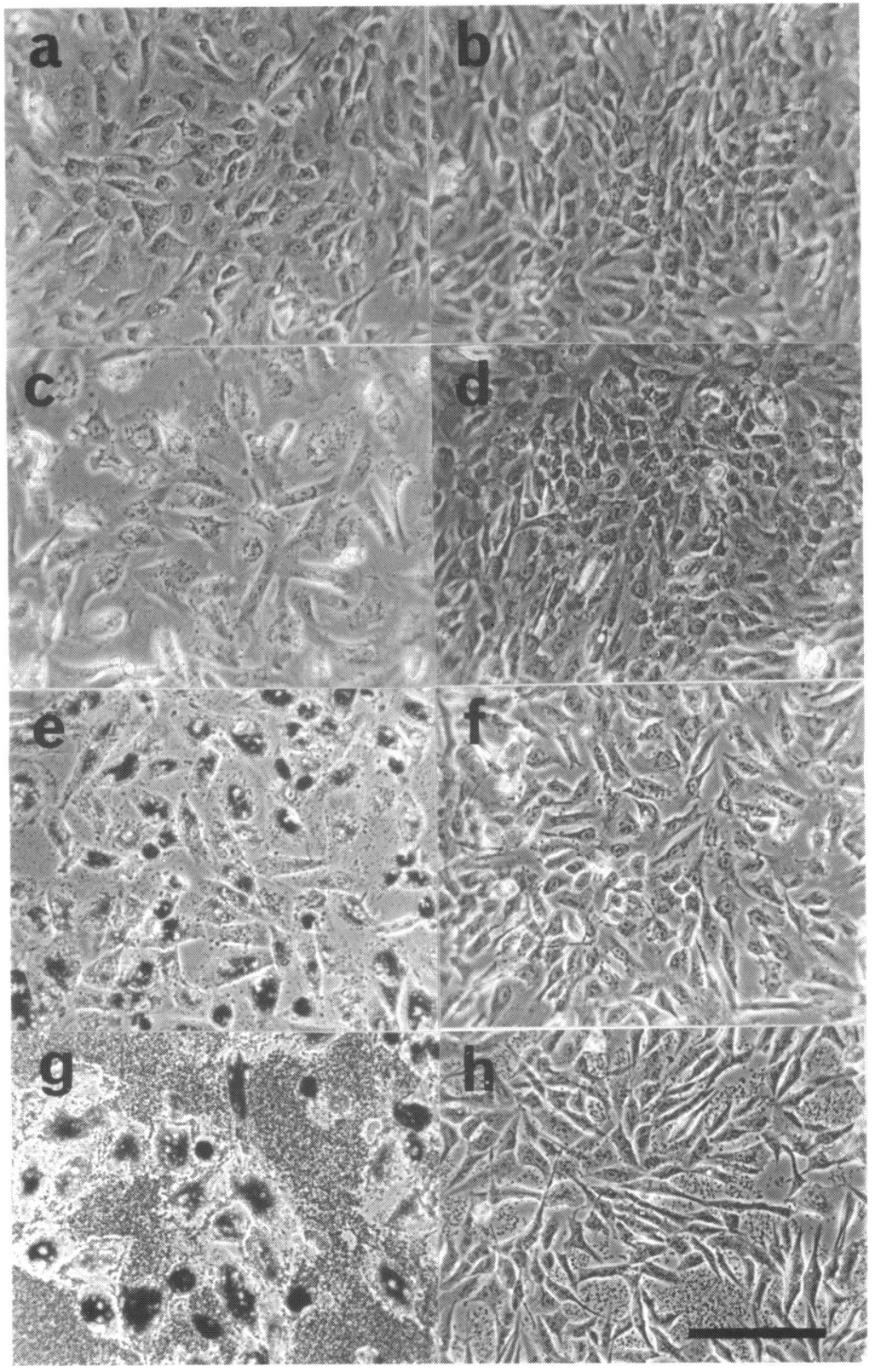

outer segment renewal rates exceed those in other regions, or a decreased lytic or metabolic activity within this area of the RPE. At present no empirical evidence supports the concept of higher turnover rates within the outer segments of foveal cones. In contrast the recent findings of Flood et al. ${ }^{13}$ showing a reduced proliferation rate in cultures of RPE cells derived from this region, and a more significant loss of activity with increasing age than that shown by cells from more peripheral regions, seems to support the second postulate, that of selectively impaired RPE.

In vitro all human RPE cells may be considered as rejuvenated in that they have recently undergone nuclear division and have shed their accumulated phagocytic load by successively sharing it between daughter cells. We have then a unique opportunity to progressively assess the senescence inducing 


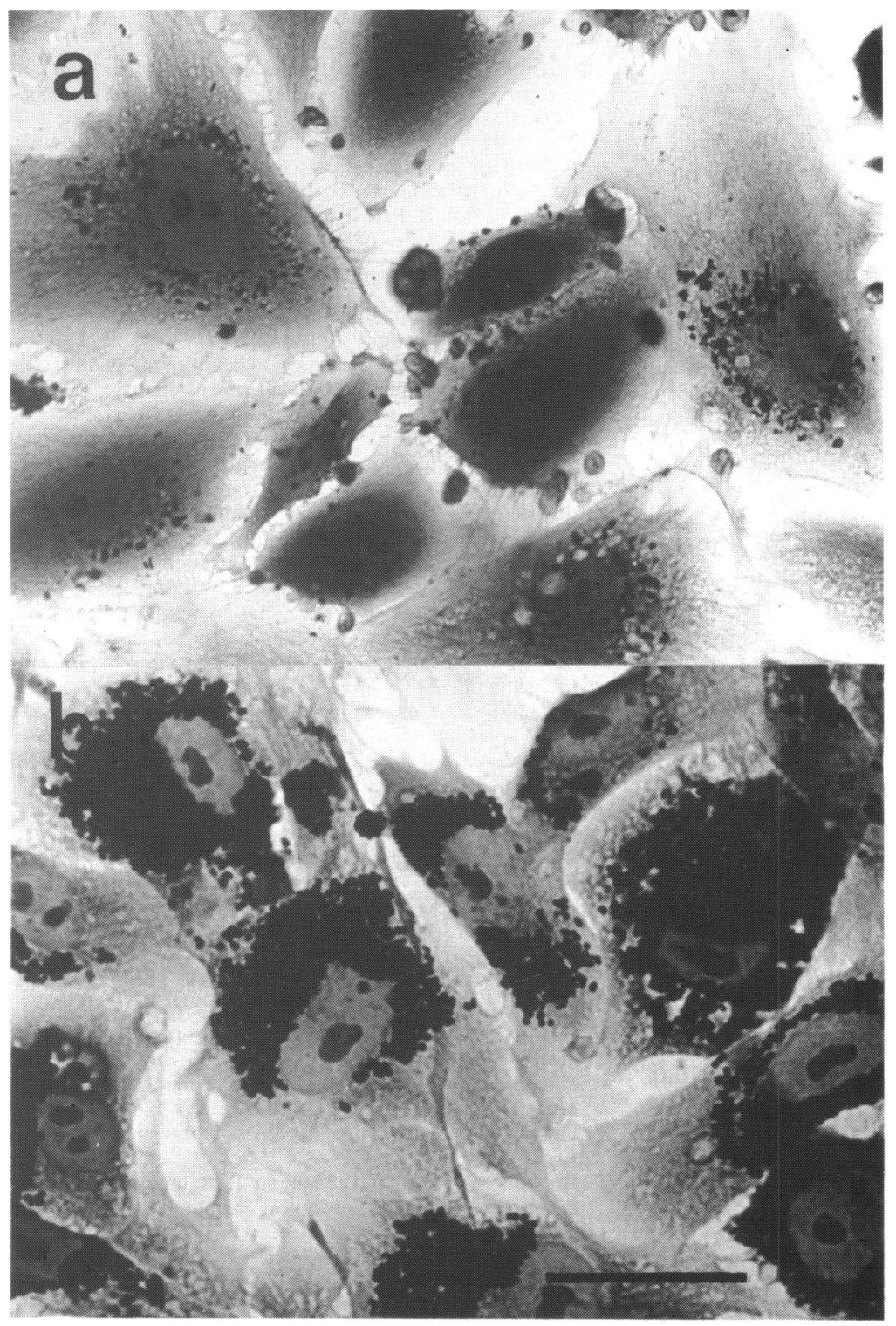

Fig. 3 High powerlight micrographs of human retinal pigment epithelial cells showing the ingestion of melanin granules and the change in cell morphology as the concentration of particles in the challenge increases: (a) $3 \times 10^{\prime}$, (b) $3 \times 10^{7}$. Note the significant shrinkage of cells at the higher concentration and the greater perinuclear accumulation of melanin. The bar market is $40 \mu$.

capabilities of a number of different particles at varying concentrations. In future we hope to examine these selectively in peripheral and macular RPE.

The preliminary results in the present study have demonstrated that, if sufficiently high concentrations of any of our test particles were taken up over a very short time span, they all induced cell death. This would seem to imply that under our conditions the ingestion phase of phagocytosis has no feedback control from sensors of cell cytoplasmic volume, and the process continues until the cells literally burst. For useful studies of cell senescence the concentra- tion of particle in the challenge must be carefully controlled to prevent cell rupture due to overengorging.

On the basis of accumulated evidence the assumption in this experiment was that melanin and latex microspheres would occupy cell volume, but not be digested and not be toxic. In contrast rod outer segments would initially occupy cell volume, but would be progressively reduced by lytic processes, while lipofuscin would occupy cell volume, would not be digested, and would perhaps be mildly toxic. As all but the lowest concentrations of microspheres, 
melanin, and lipofuscin induced profound morphological changes in the cells, we concluded that our initial challenges were too severe, or the challenge contact time was too long. However, the latency in onset for the induction of changes by challenge with rod outer segments may have been due to a limited degradation of some of the ingested particles, thus extending the time taken for cytoplasmic congestion to become apparent.

The differences observed in both time of onset and magnitude of cell detachment in relation to cells grown on the two different substrates may well be an artefact related to challenge but exaggerated by differences in adhesion, in that RPE cells always adhere more strongly to plastic than to glass.

The progressive accumulation of lipofuscin within RPE cells is thought to be implicated in a second manifestation of the aging outer retina, that of drusen formation. ${ }^{37}$ The postulated reaction sequence ${ }^{11}$ is that, as the aggregated load of lipofuscin reaches a critical level, the host cell makes extreme efforts to shed the lipofuscin and other lysosomal particles by voiding them into Bruch's membrane. However, Bruch's membrane also undergoes aging changes which result in an increased fibre content ${ }^{38}$ and therefore an increased resistance to the passage of particulate material. Extracellular debris soon begins to accumulate on its innermost aspect. Such focal excrescences expand and may resolve into one of two major types of drusen, thus becoming either dome shaped and granular or hyalinised and globular. All eyes in people over 40 have drusen at the retinal periphery..$^{34}$ In this location drusen do not lead to sight threatening consequences even though they are associated with macrophages and neovascular complexes invading the substance of Bruch's membrane..$^{39}$ In contrast, when they congregate in the posterior pole," they frequently result in major decrements in retinal function ${ }^{41}$ and senile macular degeneration.

Our model will enable the investigation of such putative interactions to be undertaken by systematically varying lipofuscin content in a number of cultures of RPE cells of different ages from various retinal locations. Further, using the current procedure in collaboration with the previously described technique for growing cultures on a permeable membrane ${ }^{23}$ it may be possible to study some of the processes involved in remodelling of basement membranes and drusen formation in vitro.

We thank the staff of the Eye Bank of Moorfields Eye Hospital for their help in obtaining normal human eyes. We are grateful to the American Retinitis Pigmentosa Foundation, the British Retinitis Pigmentosa Society, Fight for Sight, and Vision Charity for financial support. Finally we are indebted to Miss Meryl Bayly and Mr Stephen Rothery for their technical assistance.

\section{References}

1 Streeton BW, Syracuse NY. Development of the human retinal pigment epithelium and the posterior segment. Arch Ophthalmol 1969; 81: 383-94.

2 Marshall J. Interactions between sensory cells, glial cells and the retinal pigment epithelium and their responses to photocoagulation. Dev Ophthalmol 1981; 2: 308-17.

3 Young R, Bok D. Participation of the RPE in the ROS renewal processes. J Cell Biol 1969; 42: 392-403.

4 Hogan MJ, Wood I, Steinberg RH. Phagocytosis by pigment epithelium of human retinal cones. Nature 1974; 252: 305-7.

5 Marshall J. Acid phosphatase acitivity in the retinal pigment epithelium. Vision Res 1970; 10: 821-4.

6 Ishikawa T, Yamada E. The degradation of the photoreceptor outer segment within the retinal pigment epithelial cell of rat retina. J Electron Microsc 1970; 19: 85-99.

7 Marshall J, Ansell PL. Membranous inclusions in the retinal pigment epithelium: phagosomes and myeloid bodies. $J$ Anat 1971; 110: 91-104.

8 Streeton BW. The sudanophilic granules of the human retinal pigment epithelium. Arch Ophthalmol 1961; 66: 391-8.

9 Feeney L. Lipofuscin and melanin of human retinal pigment epithelium: fluorescence, enzyme, cytochemical and ultrastructural studies. Invest Ophthalmol Vis Sci 1978; 17: 583-600.

10 Wing GL, Blanchard GC, Weiter JJ. The topography and age relationship of lipofuscin concentration in the retinal pigment epithelium. Invest Ophthalmol Vis Sci 1978; 17: 601-7.

11 Hogan MJ. Role of the pigment epithelium in macular disease Ophthalmology (Rochester) 1972; 76: 64-80.

12 Young RW. A theory of central retinal disease. In: Sears ML, ed. Future directions in ophthalmic research. New Haven: Yale University Press, 1982.

13 Flood MT, Haley JE, Gouras P. Cellular aging of human retinal epithelium in vivo and in vitro. Monogr Dev Biol 1984; 17: 8093.

14 Leuenberger PM, Novikoff AB. Studies on microperoxisomes. VII. Pigment epithelial cells and other cell types in the retina of rodents. J Cell Biol 1975; 65: 324-35.

15 Marsden CD. Brain melanin. In: Woolman M, ed. Pigments in pathology New York: Academic Press, 1969: 396-420.

16 Bird AC, Marshall J. Retinal receptor disorders without known metabolic abnormalities. In: Garner A, Klintworth G, eds: Pathobiology of ocular disease. New York: Decker, 1982: 2: 1167-220.

17 Hollyfield JG. Phagocytic capabilities of the pigment epithelium. Exp Eye Res 1976; 22: 457-68.

18 Boulton M, Marshall J, Mellerio J. Retinitis pigmentosa: a quantitative study of the apical membrane of normal and dystrophic human retinal pigment epithelial cells in tissue culture in relation to phagocytosis. Graefes Arch Clin Exp Ophthalmol 1984; 221: 214-29.

19 Funahashi M, Okisaka S, Kuwabara T. Phagocytosis by monkey pigment epithelium. Exp Eye Res 1976; 23: 217-25.

20 Effron R, Szamier B, Edwards R. Selective phagocytosis of liposomes by cultured RCS rat pigment epithelium. Invest Ophthalmol Vis Sci 1981; 21: 611-6.

21 Hayashi M, Matsumoto A, Hamashima Y, Tsukahara I. Phagocytic activity of retinal pigment epithelium. Uptake of polystyrene spheres and Staphylococcus aureus. Exp Eye Res 1979; 28: 427-34.

22 Flood MT, Gouras $P$. The organization of human retinal pigment epithelium in vitro. Vision Res 1981; 21: 119-26.

23 Boulton ME, Marshall J, Mellerio J. Human retinal pigment epithelial cells in tissue culture: a means of studying inherited retinal disease. In: Cotlier E, Maumenee IH, Berman ER, eds. Genetic eye diseases: retinitis pigmentosa and other inherited eye disorders. New York: Liss, 1982; 18: 101-18.

24 Proctor PH. The role of melanin in human neurological disorders. Pigment Cell 1976; 3: 378-83. 
25 Gabel VP, Birngruber R, Hillenkamp F. Die Lichfabsorption am Augenhingrund. GSF-Bericht $A$ 55. Munich: Gesellschaft für Strahlen- und Umisettforschung, 1976.

26 Marshall J. Radiation and the aging eye. Ophthalmic Physiol Opt $1985 ; 5: 241-63$.

27 Boulton ME, Marshall JM. Repigmentation of human retinal pigment epithelial cells in vitro. Exp Eye Res 1985; 41: 209-18.

28 Boulton ME, Marshall J, Mellerio J. Retinitis pigmentosa: a preliminary report on tissue culture studies of retinal pigment epithelial cells from eight affected human eyes. Exp Eye Res 1983; 37: 307-13.

29 Boulton ME, Marshall J. A mechanistic approach to the inherited retinal dystrophies and the role of tissue culture as an investigative probe. In: Sheffield JB, Hilfer SR, eds. Heredity and visual development. New York: Springer, 1985; 4: 11570.

30 Papermaster DS. Preparation of retinal rod outer segments. In: Packer L, ed. Visual pigments and purple membranes. Methods Enzymol 1982; 81: 48-52.

31 Paul J. Cell and tissue culture. Edinburgh, London, and New York: Churchill Livingstone. 1975.

32 Feeney L, Mixon RN. An in vitro model of phagocytosis in bovine and human retinal pigment epithelium. Exp Eye Res 1976; 22 : 533-48.

33 Medical Research Council. Diseases of the eye: Working party report submitted to Neurobiology and Mental Health Board. London: Medical Research Council, 1983.

34 Gibson JM, Rosenthal AR, Lavery J. A study of the prevalence of eye disease in the elderly in an English community. Trans Ophthalmol Soc UK 1985; 104: 196-203.

35 Marshall JM. Light damage and ageing in the human macula. Research and Clinical Forums. New perspectives in ophthalmology 1985; 7: 27-43.

36 Feeney-Burns L, Hilderbrand ES, Eldridge S. Aging human RPE: morphometric analysis of macular, equatorial and peripheral cells. Invest Ophthalmol Vis Sci 1984; 25: 195-200.

37 Eagle RC. Mechanisms of maculopathy. Ophthalmology (Rochester) 1984; 91: 613-26.

38 Grindle CFJ, Marshall J. Ageing changes in Bruch's membrane and their functional implications. Trans Ophthalmol Soc UK 1978; 99: 172-5.

39 Foos RY, Trese MT. Chorioretinal junction. Vascularisation of Bruch's membrane in the peripheral fundus. Arch Ophthalmol 1982; 100: 1492-503.

40 Gass JD. Drusen and disciform macular detachment and degeneration. Arch Ophthalmol 1973; 90: 206-17.

41 Sarks SH. Ageing and degeneration in the macular region: a clinicopathological study. BrJ Ophthalmol 1976; 60: 324-40.

Accepted for publication 14 February 1986. 